\title{
AC 2009-992: ENHANCEMENT OF STUDENT LEARNING IN EXPERIMENTAL DESIGN USING VIRTUAL LABORATORIES
}

\section{Milo Koretsky, Oregon State University}

Milo Koretsky is an Associate Professor of Chemical Engineering at Oregon State University. He currently has research activity in areas related to thin film materials processing and engineering education. He is interested in integrating technology into effective educational practices and in promoting the use of higher level cognitive skills in engineering problem solving. Dr. Koretsky is a six-time Intel Faculty Fellow and has won awards for his work in engineering education at the university and national levels.

\section{Christine Kelly, Oregon State University}

Christine Kelly is an Associate Professor of Chemical Engineering at Oregon State University. She currently has research activity in biological production and use of ligninolytic enzymes in biomass deconstruction for bioproducts and biofuels manufacture. She also has interests in developing tools to promote the use of higher cognitive skills in engineering coursework. Dr. Kelly recently earned OSU's Austin-Paul Engineering FacultyAward for mentoring students. 


\section{Enhancement of Student Learning in Experimental Design using Virtual Laboratories}

\section{Introduction}

Capstone courses in which students have an opportunity to practice engineering are an important aspect of undergraduate engineering curriculum. In the last 20 years, capstone courses have been integrated into engineering curricula nationwide in response to ABET accreditation requirements and feedback from industry. ${ }^{1}$ In addition to providing students the opportunity to practice engineering, capstone courses facilitate the development of creative and critical thinking, which are crucial in the practice of engineering. By design, capstone courses are the mechanism by which students apply the core concepts that are critical to their discipline to solve an open-ended problem. This type of activity should enable students to engage in a deeper level of cognition than experienced earlier in their curriculum, which focuses more on analytical skills. In the context of providing an effective capstone experience, we have developed two virtual laboratories, the Virtual Chemical Vapor Deposition laboratory and the Virtual BioReactor laboratory. ${ }^{2-5}$ In a virtual laboratory, simulations based on mathematical models implemented on a computer can replace the physical laboratory. Virtual laboratories have been developed and integrated into engineering curricula. ${ }^{6-10}$ However, relative to the work on instructional development, the degree of assessment has been sparse. ${ }^{11-13}$

Our intent is to provide students a capstone experience in which they can apply experimental design in a context similar to that of a practicing engineer in industry. The objectives of this research are to explore the types of cognition and social interactions of student teams as they engage in these virtual laboratories, to determine the role of instructional design in the response of student teams, and to ascertain whether virtual laboratories can effectively promote types of learning that are difficult or impossible to achieve from physical laboratories.

\section{Objectives}

The specific objectives of the NSF CCLI Phase 2 project are to:

1. Create the following learning materials and teaching strategies based on virtual laboratories:

A. Enhance the Virtual CVD laboratory by including interactive reflection tools (e.g., interactive lab notebook, a virtual supervisor), improved treatment of variability and cost, non-radial symmetry, and a new module on statistical process control.

B. Using an analogous instructional design, develop a virtual laboratory of a bioreactor, the Virtual Bioreactor laboratory, a process in a different industry.

C. Develop level appropriate assignments to use at the high school and community college levels.

2. Develop faculty expertise and implement the virtual laboratories at the BS and graduate levels by: 
A. Delivering the Virtual Bioreactor laboratory and the revised Virtual CVD laboratory in $\mathrm{ChE} / \mathrm{BioE} / \mathrm{EnvE} \mathrm{414}$, the integrated term of the capstone senior laboratory in the School of Chemical, Biological and Environmental Engineering at Oregon State University.

B. Implementing the Virtual CVD laboratory remotely in the undergraduate ChE program at UC Berkeley and in an accelerated MS graduate program in Semiconductor Processing at the University of Oregon, and implementing the Virtual Bioreactor laboratory at the University of Tennessee.

3. Demonstrate the Virtual CVD laboratory is an effective and transportable learning tool that can be tailored to a variety of levels. Develop faculty expertise and then deliver at approximately 10 high schools and 10 community colleges.

4. Assess learning and evaluate the virtual laboratories in the following ways:

A. Continue to qualitatively and quantitatively study the ways students learn using the Virtual CVD laboratory. Further develop the "think-aloud" method used in the proofof-concept stage. Examine how differing discipline specific knowledge combinations that groups of students bring to the execution of the virtual laboratory facilitate or inhibit the development of cognitive processes in experimental design.

B. Assess student learning using the Virtual Bioreactor laboratory in a similar way. Examine the extent to which the cognitive processes and skills elicited by the innovative approach towards student learning of experimental design demonstrated in the Virtual CVD laboratory also applies to the Virtual Bioreactor laboratory. Use both the Virtual CVD and the Virtual Bioreactor laboratories in the same class to assess the extent to which practice effects influence the approach taken by students (i.e., will they perform in a different manner the second time they go through the design process).

C. Assess the implementation of the Virtual CVD laboratory at the High school and community college levels.

5. Disseminate results and materials to the professional community, including continued development of a web site, presentations at national meetings and published papers in the engineering education literature.

6. Integrate the laboratory modules into the outreach activities currently in place in the ChE department.

\section{Activities}

The following activities are underway:

- Software DeVElopment

1. The major effort in software development has resulted in a functional virtual laboratory of a bioreactor, the Virtual Bioreactor laboratory. ${ }^{5}$ The Virtual BioR Laboratory is based on an industrial stirred-tank fed-batch bioreactor and can be used for different functions, such as production of a product or degradation of waste. The module allows for a unique set of instructor specified parameters (such as temperature optimum, degree of substrate inhibition, maximum specific growth rate, etc.) for each group in the class. A 3D Student Interface is being developed; the Student Interface is presently HTML based. 
- CURriculum DeVelopment

The following learning materials and teaching strategies, based on virtual laboratories, were created:

1. Using an instructional design that was analogous to the Virtual Chemical Vapor Deposition Laboratory, university level curricular materials have been developed for the Virtual Bioreactor laboratory. The target is for a capstone process laboratory design project in the senior year where students are instructed to find operating conditions that maximize volumetric productivity in the bioreactor. Additionally faculty expertise was developed in the Bioengineering program at Oregon State University (OSU).

2. A second set of curricular materials have been constructed that are developmentally appropriate for use in chemistry and pre-engineering classes at the high school level. ${ }^{14}$ These materials scaffold the complex content in the college level course materials.

\section{- IMPLEMENTATION}

1. The delivery of Virtual Laboratories at OSU is shown in Table 1. The Virtual CVD laboratory (VCVD) has been used since Winter 2005 (W 2005). The Virtual Bioreactor laboratory (VBioR) was used for the first time in Fall 2007 in ChE/BioE/EnvE 414, the integrated term of the capstone senior laboratory in the School of Chemical, Biological and Environmental Engineering.

Table 1. Summary of experimental activity of the Virtual Laboratories at Oregon State University

\begin{tabular}{|c|c|c|c|c|c|c|c|}
\hline Class & Lab & Term & Students & Groups & Runs & Measurements & Virtual Cos \\
\hline ChE 444 & VCVD & W 05 & 24 & 8 & 97 & 2,672 & $\$ 685,400$ \\
\hline ChE 444 & VCVD & W 06 & 28 & 8 & 122 & 2,241 & $\$ 778,075$ \\
\hline SESEY & VCVD & Su 06 & 4 & 4 & 146 & 6,413 & $\$ 1,210,975$ \\
\hline ChE 414 & \multirow{2}{*}{ VCVD } & \multirow{3}{*}{ F 06} & \multirow{3}{*}{52} & \multirow{3}{*}{23} & 384 & \multirow{2}{*}{5,293} & \multirow{2}{*}{$\$ 2,316,975$} \\
\hline Project 1 & & & & & (50 & & \\
\hline $\begin{array}{c}\text { Project } 2 \\
\text { (SPC) }\end{array}$ & VCVD & & & & 572 & 33,136 & $\$ 5,345,200$ \\
\hline ChE 444 & VCVD & W 07 & 12 & 4 & 60 & 1,915 & $\$ 443,625$ \\
\hline \multirow{2}{*}{ CBEE 414} & VCVD & \multirow{2}{*}{ F07 } & 15 & 7 & 93 & 1,722 & $\$ 594,150$ \\
\hline & VBioR & & 37 & 14 & 237 & 7,449 & $\$ 2,894,815$ \\
\hline ChE 444 & VCVD & W08 & 12 & 4 & 45 & 611 & $\$ 270,825$ \\
\hline SESEY & VCVD & Su 08 & 2 & 1 & 10 & 387 & $\$ 79,025$ \\
\hline \multirow{2}{*}{ CBEE 414} & VCVD & \multirow{2}{*}{ F08 } & 41 & 14 & 290 & 8250 & $\$ 2,068,750$ \\
\hline & VBioR & & 39 & 13 & 243 & 8748 & $\$ 3,540,897$ \\
\hline ChE 444 & VCVD & W08 & 6 & 2 & & & \\
\hline Total & & & 272 & 102 & 2299 & 78837 & $\$ 20,228,712$ \\
\hline
\end{tabular}


2. A major objective of this project is to facilitate the implementation of the Virtual Laboratories at a number of universities beyond Oregon State University to develop evidence of the portability and generalizable use of the virtual laboratory instructional materials. Table 2 lists the institutions that have used the Virtual CVD laboratory remotely.

Table 2. Summary of experimental activity of the Virtual CVD Laboratories outside OSU

\begin{tabular}{|c|c|c|c|c|c|c|}
\hline Class & Term & Students & Groups & Runs & Measurements & Virtual Cost \\
\hline U Oregon & Su 06 & 11 & 3 & 40 & 538 & $\$ 240,350$ \\
\hline U Oregon & Su 07 & 10 & 3 & 57 & 610 & $\$ 330,750$ \\
\hline UC Berkeley & S 07 & 25 & 25 & 96 & 8,980 & $\$ 1,153,500$ \\
\hline $\begin{array}{l}\text { Crescent Valley HS: } \\
\text { Chemistry }\end{array}$ & S 08 & 210 & 92 & 1,100 & 53,971 & $\$ 9,547,825$ \\
\hline $\begin{array}{l}\text { Crescent Valley HS: } \\
\text { Engineering }\end{array}$ & S 08 & 53 & 31 & 424 & 10,899 & $\$ 2,937,425$ \\
\hline U Oregon & $\mathrm{Su} 08$ & 16 & 4 & 50 & 1,137 & $\$ 460,275$ \\
\hline $\begin{array}{l}\text { Virtual Chemical } \\
\text { Vapor Deposition } \\
\text { Workshop }\end{array}$ & Su 08 & 15 & 7 & 165 & 5,014 & $\$ 1,201,050$ \\
\hline $\begin{array}{l}\text { Virtual Chemical } \\
\text { Vapor Deposition } \\
\text { Workshop }\end{array}$ & F08 & & & 98 & 3220 & $\$ 731,500$ \\
\hline North Dakota State & F 08 & 9 & 3 & 18 & 226 & $\$ 106,950$ \\
\hline UC Berkeley & S 09 & \multicolumn{5}{|c|}{ In Progress } \\
\hline Hudson Valley CC & S 09 & 16 & 7 & 40 & 1116 & $\$ 283,700$ \\
\hline Wilkes University & S 09 & 14 & 7 & 48 & 1139 & $\$ 325,425$ \\
\hline North Seattle CC & S 09 & 6 & 6 & 53 & 1213 & $\$ 355,975$ \\
\hline North Eugene HS & S 09 & 67 & 33 & 279 & 6813 & $\$ 1,905,975$ \\
\hline Crescent Valley HS & S 09 & \multicolumn{5}{|c|}{ In Progress } \\
\hline Cascade HS & S 09 & 22 & 10 & 69 & 1593 & $\$ 464,475$ \\
\hline Ontario HS & S 09 & \multicolumn{5}{|c|}{ In Progress } \\
\hline Total & & 474 & 231 & 2537 & 96469 & $\$ 20,045,175$ \\
\hline
\end{tabular}

- Assessment AND Evaluation

A major activity is the development of an assessment system to evaluate the effectiveness of this tool in promoting the development of complex knowledge structures and integration of higher order thinking skills. The evaluation model that best fits the Virtual Laboratories is one that closely integrates assessment results to improve their design and implementation. Evidence of the development of the cognitive capacity of students 
requires the design and interpretation of an assessment system that mirrors the ways in which knowledge is developed and applied in the working environment of engineers. The development of an assessment system tied through backwards design to the educational objectives that frame the content and processes of the courses is viewed to be one of the products of this project. In addition, the evaluation plan will measure the transportability of the Virtual CVD Learning Platform to support its use in a variety of engineering and science courses.

Three research questions have been addressed:

1. What is the nature of the experimental design process that students apply in the virtual laboratories?

2. What types of cognitions are elicited in students when completing the virtual laboratory projects?

3. How does students' tolerance for ambiguity change while completing the virtual laboratories?

Three measurement tools are being used to collect data for analysis in this project:

1. Think-Aloud Protocol: The cornerstone of the data collection utilizes the "think-aloud" technique, in which students' performances are observed and recorded while they verbalize their thought processes. This technique has been shown to give insight to their cognitive processes, especially in situations where complex knowledge structures are evoked and higher order critical thinking ability is needed. During data collection, students are instructed to merely verbalize their thoughts and discouraged from describing or explaining their thoughts as part of the "think aloud." The digital audio files are used for further analysis, and specific passages are transcribed as needed. Because of the situated nature of the virtual laboratories, completion of the project itself results in the development of evidence about students' performances on an articulated set of component tasks. Therefore, a task analysis of the students' approach to the project is an essential aspect of the virtual laboratory assessment. In the case of the virtual laboratory projects in this study, the solution by any student group or, in contrast, by any "expert" is only one of numerous possible solutions. We are seeking to compare a set of solutions characteristic of the student teams to that of an expert. Comparing the nature of the respective solution paths allows elucidation of the difference between how expert and novice "see" this project. Additionally, the "think aloud" studies have revealed certain developmental changes during the course of the project. Thus, there are specific changes on a time-scale much shorter of that of development from novice to expert. One such change that has been demonstrated is the growth in tolerance for ambiguity. In summary, the qualitative method has evolved to entail a detailed task analysis with corresponding evaluation of the quality of each task, a rating of the group's tolerance for ambiguity, and an analysis of the impact that social interactions had on key decision points.

\section{Data Logging from the Virtual Laboratory and Other Student Work: The virtual} laboratories themselves provide useful quantitative data about the student's solution path. A summary of all students' interactions with the equipment and all raw data is available through the instructor interface. A summative evaluation of the quality of the student team's performance is also calculated. This feature allows the interactive aspects of their 
laboratory practice to be analyzed. In addition to their parameter choices, the timing of the runs gives information about the approach that students are adopting in the laboratory. In the present instructional design used at OSU, students are required to complete the following task components: a design memorandum and instructor coaching session that is completed prior to the students performing virtual experiments; a project update memorandum; a project journal; a written report; and an oral presentation. These assignments form records of the student thought processes as they engage in the project. For example, the number of high cognition statements in student reports was counted and correlated to the performance of their final process "recipe."

3. Student Survey: Finally, a student survey has been developed to describe the differing student perceptions of the learning that they were to take away from the three different laboratory experiences, two physical laboratories and the virtual laboratory. A set of survey questions was provided to the students in ChE/BioE/EnvE 414 senior laboratory class in Fall 2007 and Fall 2008 as an assignment. The survey questions were asked after the students had completed each of the three laboratories. The survey was implemented, in general, as soon as possible after the final laboratory report for that given laboratory had been turned in. There were, in some cases, overlap in that the content for the next laboratory had commenced. Students' perceptions of what they were intended to learn provide a lens into their metacognitive processes. Research in metacognition in engineering education has demonstrated the efficacy of providing students with learning environments that enhance students' reflection upon and regulation of their own learning. This research seeks to identify the ways that student knowledge and awareness of their own learning might evolve as they move through 3 structured laboratory experiences. A methodology for analysis has been developed including coding protocol and analysis for three of the questions and analysis development to improve inter-rater reliability and to check if there is a bias in the analysis. This activity is described in more detail elsewhere. ${ }^{15}$

- WORKSHOP

Two workshops for college and high school faculty has been delivered at Oregon State University. The intent was to demonstrate the utility of the Virtual CVD laboratory as a learning platform at different curricular levels and to develop faculty expertise. This activity is described in more detail elsewhere. ${ }^{14}$

\section{Acknowledgements}

The authors are grateful for support provided by the Intel Faculty Fellowship Program and the National Science Foundation's Course, Curriculum and Laboratory Improvement Program, under Proof-of-Concept grant DUE-0442832 and Phase 2 grant DUE-0717905. Any opinions, findings, and conclusions or recommendations expressed in this material are those of the authors and do not necessarily reflect the views of the National Science Foundation. 


\section{References}

1. Dutson, A., Todd, R., Magleby, S. \& Sorensen, C. (1997). A Review of Literature on Teaching Engineering Design Through Project-Oriented Capstone Courses. J. Eng. Ed., 86, 17-28.

2. Koretsky, M.D., D. Amatore, C. Barnes, and S. Kimura, (2008). Enhancement of Student Learning in Experimental Design using a Virtual Laboratory," IEEE Trans. Ed., Special Issue on Virtual Laboratories, 51, 76.

3. Koretsky, Milo D., Sho Kimura, Connelly Barnes Derek-Meyers Graham, and Danielle Amatore (2006). Experiential Learning of Design of Experiments Using a Virtual CVD Reactor. Proceedings of the 2006 American Society for Engineering Education Annual Conference \& Exposition, Session 2613.

4. Amatore, Danielle, Edith Gummer, and Milo D. Koretsky (2007). Instructional Design and Evaluation of a Virtual Laboratory in Nanoelectronics Processing. Proceedings of the 2007 American Society for Engineering Education Annual Conference \& Exposition.

5. Christine Kelly, Edith Gummer, Philip Harding and Milo Koretsky (2008). Teaching Experimental Design using Virtual Laboratories: Development, Implementation and Assessment of the Virtual Bioreactor Laboratory. Proceedings of the 2008 American Society for Engineering Education Annual Conference \& Exposition.

6. Jayakumar, S., Squires, R.G., Reklaitis, G.V., Andersen, P.K. \& Dietrich, B.K. (1995). The Purdue-Dow Styrene Butadiene Polymerization Simulation. J. Eng. Edu., 84, 271 -277.

7. Hodge, H., Hinton, H.S., \& Lightner, M. (2001). Virtual Circuit Laboratory. J. Eng. Edu., 90, 507-511.

8. Kuriyan, K., Muench, W. \&Reklaitis, G.V. (2001). Air Products Hydrogen Liquifaction Project: Building a Web-Based Simulation of an Industrial Process. Comput. Appl. Eng. Educ. 9, 180-91.

9. Harmon, T.C., Burks, G.A., Giron, J.J., Wong, W., Chung, G.K.W.K., \& Baker, E. (2002). An Interactive Database Supporting Virtual Fieldwork in an Environmental Engineering Design Project. J. Eng. Edu., 91, 167-176.

10. Richardson, J., Adamo-Villani, N., Carpenter, E. \& Moore, G. (2006). Designing and Implementing a Virtual 3D Microcontroller Laboratory Environment. 36th ASEE/IEEE Frontiers in Education Conference Proceedings.

11. Chung, G.K.W.K., Harmon, T.C., \& Baker, E. (2001). The Impact of a Simulation-Based Learning Design Project on Student Learning," IEEE Trans. Educ., 44, 390-398.

12. Campbell, J., Bourne, J., Mosterman, P., \& Brodersen, A. (2002). The Effectiveness of Learning Simulations for Electronic Laboratories. J. Eng. Edu., 91, 81-87.

13 Lindsay, E. D. \& Good, M. C. (2005). Effects of Laboratory Access Modes upon Learning Outcomes," IEEE Trans. Ed., 48, 619-631.

14. Koretsky, Milo D., Debra Gilbuena, and Adam Kirsch (2009). Engaging High School Students in Engineering, Science and Technology using Virtual Laboratories. Proceedings of the 2009 American Society for Engineering Education Annual Conference \& Exposition.

15. Koretsky, Milo D. , Christine Kelly, Philip Harding, and Edith Gummer (2009). Comparison of Student Perceptions of Virtual and Physical Laboratories. Proceedings of the 2009 American Society for Engineering Education Annual Conference \& Exposition. 